\title{
Vermicompost and deep tillage system better than chemical amendments and conservative tillage to improve saline-alkaline soils and wheat productivity
}

\author{
Zheli Ding ${ }^{1}$, Ahmed Kheir ${ }^{2}$, Osama Ali ${ }^{3}$, Emad Hafez ${ }^{4}$, Essam Elshamey ${ }^{5}$, Zhaoxi Zhou $^{1}$, \\ Bizun Wang ${ }^{1}$, Xing'e Lin ${ }^{1}$, Ahmed Fahmy ${ }^{6}$, and Mahmoud Seleiman ${ }^{3}$ \\ ${ }^{1}$ Haikou Experimental Station, Chinese Academy of Tropical Agricultural Sciences \\ (CATAS), Haikou, China \\ ${ }^{2}$ Agricultural Research Center \\ ${ }^{3}$ Department of Crop Sciences, Faculty of Agriculture, Menoufia University, 32514, Shibin \\ El-kom, Egypt \\ ${ }^{4}$ Agronomy Department, Kafrelsheikh University, Egypt \\ ${ }^{5}$ Field Crops Research Department, Agricultural Research Centre, 12112, Giza, Egypt \\ ${ }^{6}$ Atomic Energy Authority, Nuclear Research Centre, Soil \& Water Research Department, \\ Abou-Zaabl, 13759, Egypt
}

May 5, 2020

\begin{abstract}
Land degradation due to soil salinity and alkalinity is considered a serious concern in arid ecosystems. Due to arid climate even, normal soils are converted to saline-alkaline soils. Despite the importance of conservative tillage in carbon sequestration and improving soil properties, its effect on saline-alkaline soils even under amendments application remains unknown. In addition, application of soil conditioners particularly vermicompost with tillage systems on saline soil has less attention so far. Therefore, the present study assigned to explore the combined effects of inorganic (sulfuric acid and gypsum) and organic (vermicompost) soil amendments and tillage systems (zero, reduced and deep tillage) on saline-alkaline soil properties and wheat productivity. Deep tillage with vermicompost application significantly reduced soil electrical conductivity (EC), exchangeable sodium percentage (ESP), penetration resistance (PR) and bulk density (BD) and increased soil hydraulic conductivity (HC), mean weight diameter (MWD) and aggregation index (AI) compared to control. Deep tillage showed a significant improvement of saline-sodic soils, despite increasing (SOC) with zero and reduced tillage. Moreover, vermicompost and sulfuric acid applications with deep tillage increased wheat grain yield significantly compared to control. Vermicompost application surpassed chemical amendments in improving properties of saline-alkaline soils, and consequently enhanced growth and yield of wheat, providing that using deep tillage as an appropriate tillage system. Although deep tillage reduced soil organic carbon, application of vermicompost not only compensated this reduction but also increased SOC significantly. This could confirm the importance of combining deep tillage and vermicompost as an acceptable method in reclaiming such soil environmentally
\end{abstract}

\section{Hosted file}

Main manuscript.docx available at https://authorea.com/users/298512/articles/427903vermicompost-and-deep-tillage-system-better-than-chemical-amendments-and-conservativetillage-to-improve-saline-alkaline-soils-and-wheat-productivity 


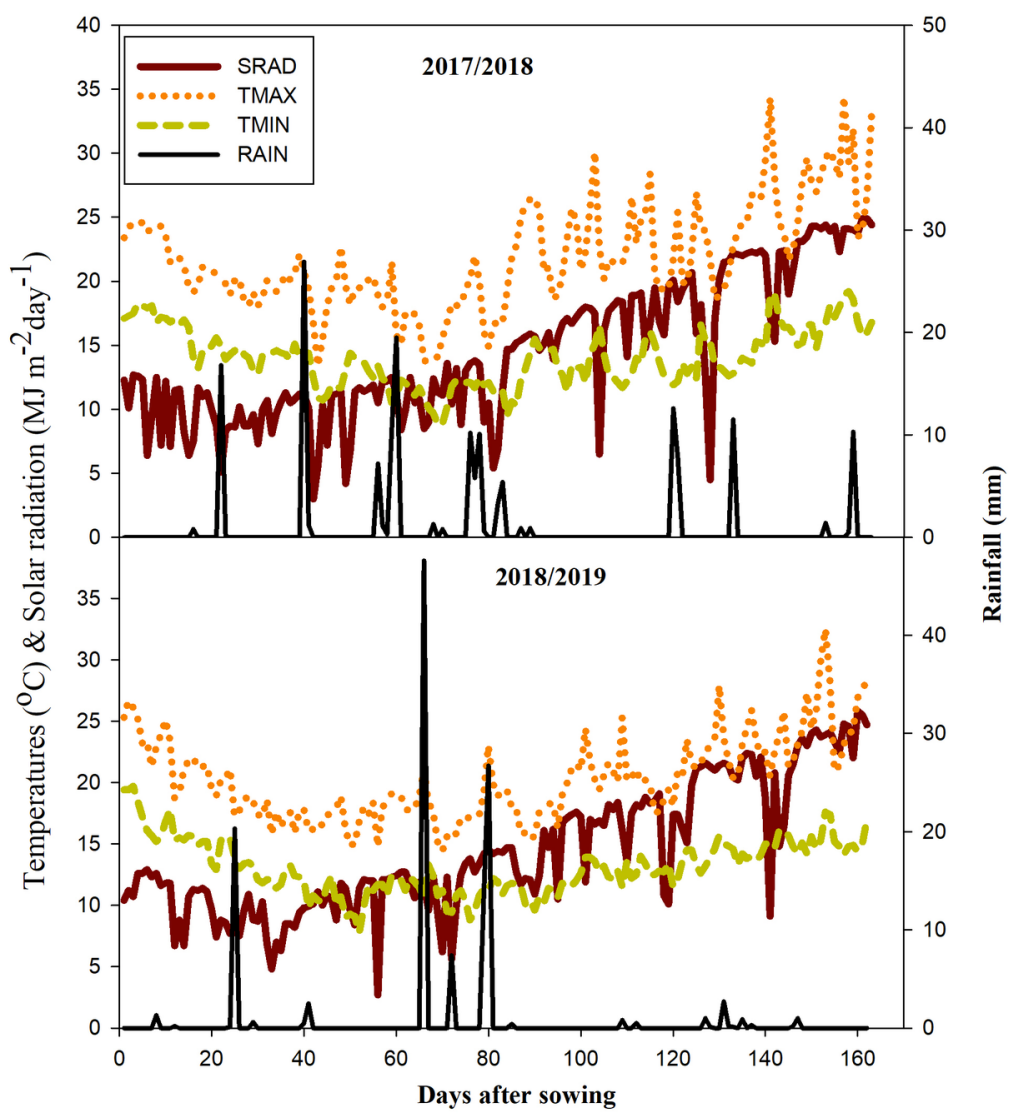



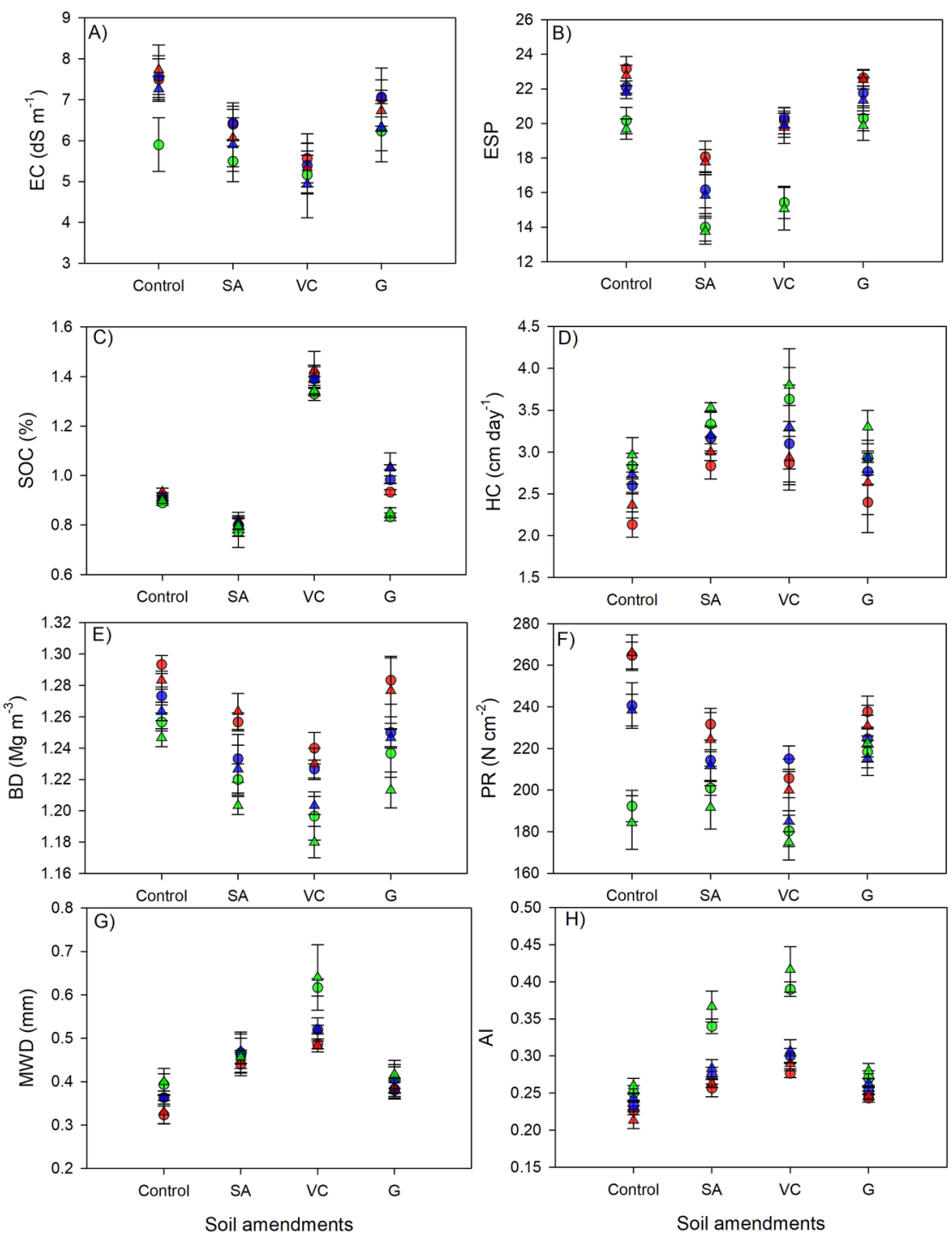


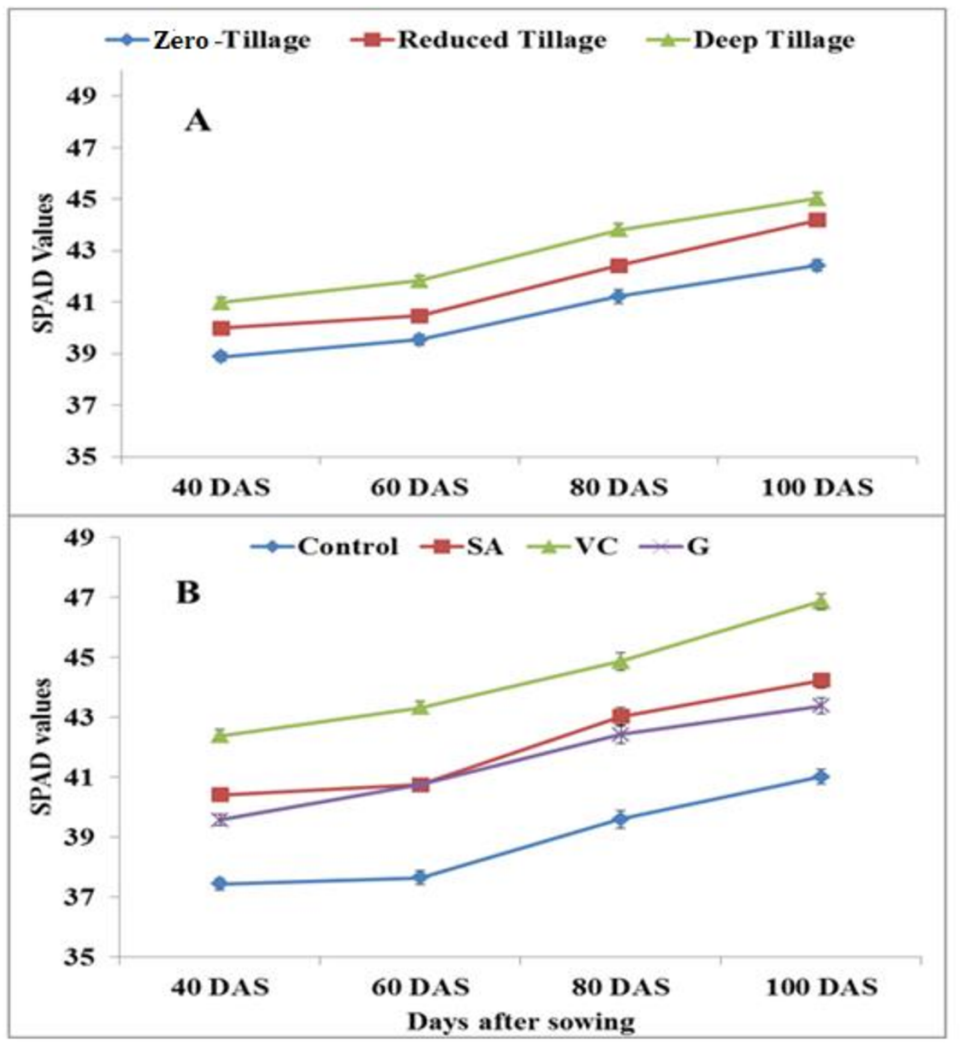


A)
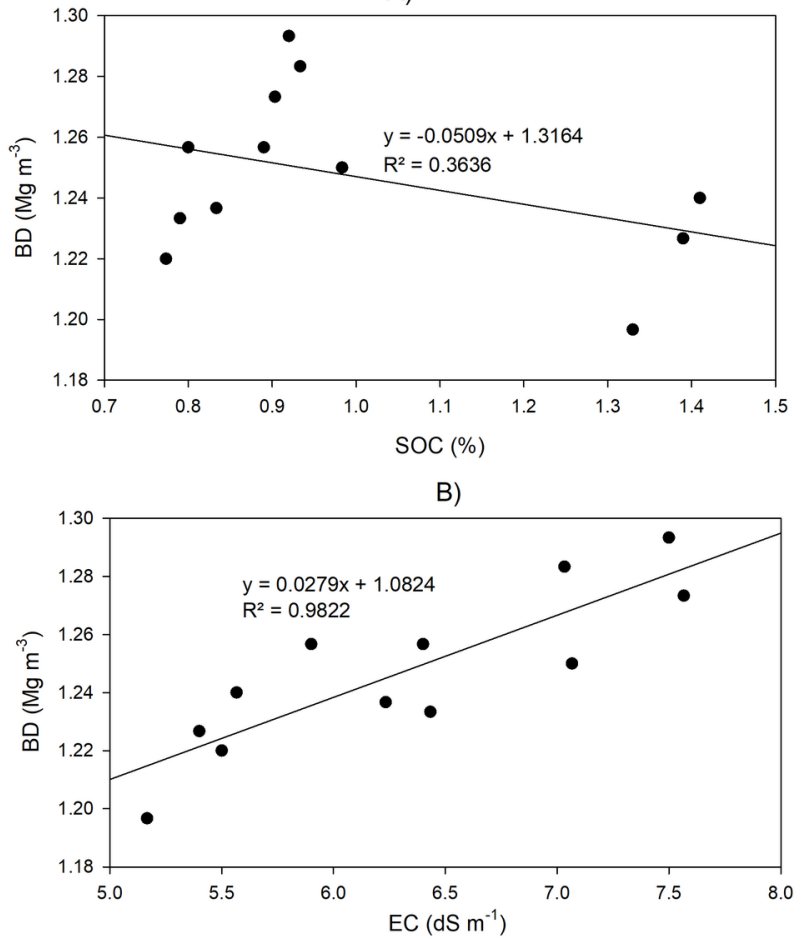

C)

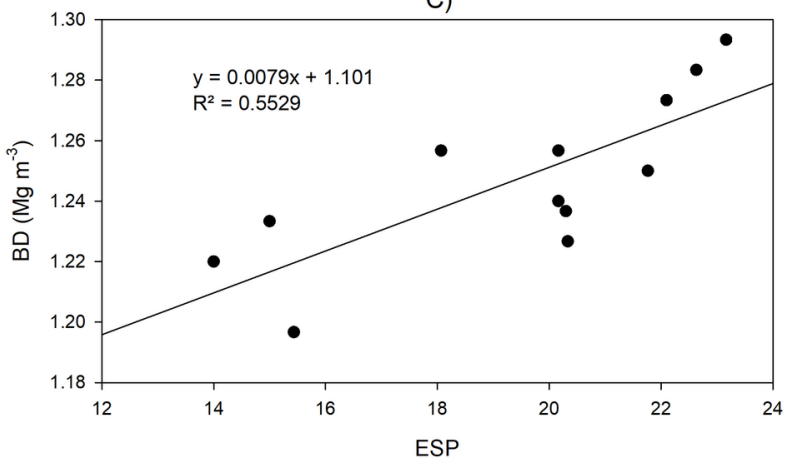


A)

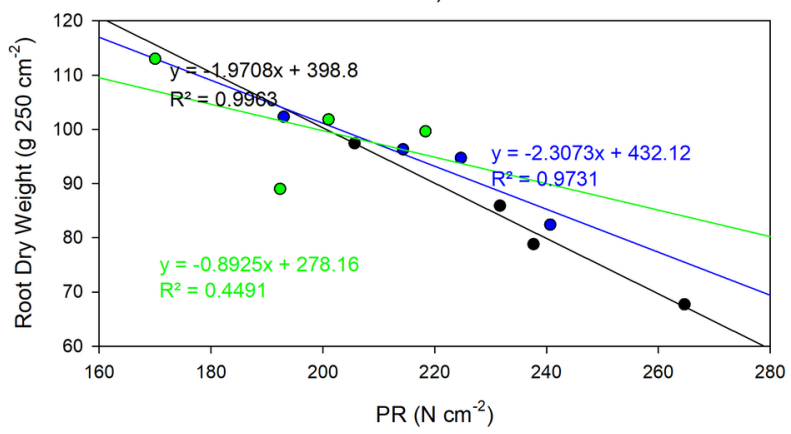

B)

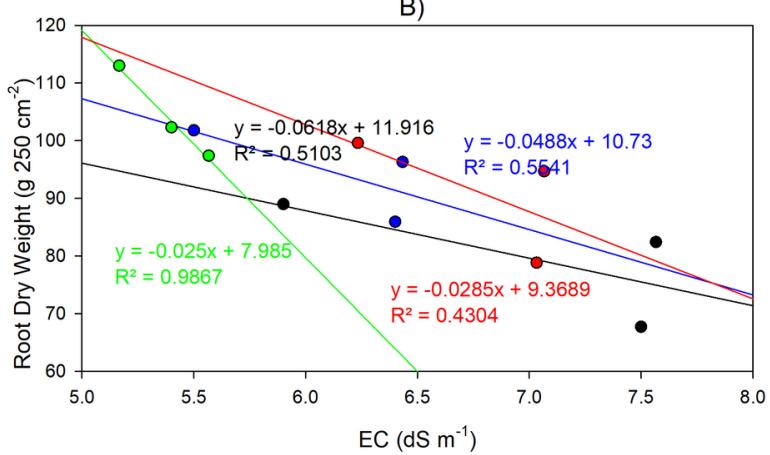

C)

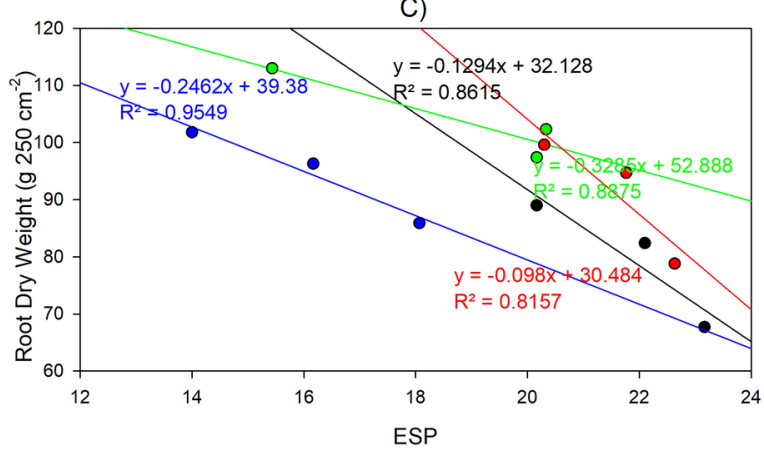

\section{Hosted file}

Tables.docx available at https://authorea.com/users/298512/articles/427903-vermicompost-anddeep-tillage-system-better-than-chemical-amendments-and-conservative-tillage-to-improvesaline-alkaline-soils-and-wheat-productivity 